\title{
Trial of glucose versus fat emulsion in preparation of amphotericin for use in HIV infected patients with candidiasis
}

\author{
Pascal Y Chavanet, Isabelle Garry, Natacha Charlier, Denis Caillot, Jean-Paul Kisterman, \\ Michel D’Athis, Henri Portier
}

\begin{abstract}
Objectives - To compare the tolerance, efficacy, and pharmokinetics of amphotericin deoxycholate (Fungizone) prepared in a parenteral fat emulsion (Intralipid $20 \%$ ) or glucose in HIV patients with candidiasis.
\end{abstract}

Design-Non-blind randomised controlled trial.

Setting-University hospital; tertiary clinical care.

Patients-22 HIV positive patients with oral candidiasis.

Interventions-Amphotericin $1 \mathrm{mg} / \mathrm{kg} / \mathrm{day}$ given on four consecutive days as a one hour infusion dissolved in either 5\% glucose (amphotericinglucose) or parenteral fat emulsion at a final concentration of $2 \mathrm{~g} / \mathrm{l}$ fat emulsion (amphotericin-fat emulsion).

Main outcome measures-Clinical tolerance (fever, chills, sweats, nausea, arterial pressure, and pulse rate); biological tolerance (serum creatinine, electrolyte, and magnesium values); clinical score of candidiasis; and serum concentrations of amphotericin.

Results - 11 patients were enrolled in each group. All the amphotericin-fat emulsion infusions were given without serious problem whereas four amphotericin-glucose infusions were stopped because of renal impairment $(n=3)$ or severe chills $(n=2)$, or both. For patients completing the amphotericin-glucose treatment creatine concentration increased by $42 \mu \mathrm{mol} / \mathrm{l}$; four of seven patients had at least one creatinine value $\geqslant 133 \mu \mathrm{mol} / 1$ versus one of 11 receiving amphotericin-fat emulsion. Magnesium concentration fell significantly with amphotericin-glucose but not with amphotericin-fat emulsion. Clinical side effects were noted in 36/38 infusions with amphotericinglucose but 10/44 with amphotericin-fat emulsion. Oral candidiasis score was reduced similarly in both groups. Serum amphotericin concentrations were significantly lower and the volume of distribution of the drug higher after infusion of amphotericin-fat emulsion than after amphotericin-glucose.

Conclusions-Clinical and renal toxicity of amphotericin are reduced when the drug is prepared in fat emulsion. Preparation is simple and cost effective. Its efficacy is similar to that of conventional amphotericin.

Service des Maladies Infectieuses, Hopital du Bocage, BP 1542, 21034

Dijon Cedex, France Pascal Y Chavanet Isabelle Garry

Natacha Charlier, pharmucist Denis Caillot

Jean-Paul Kisterman

Michel D'Athis

Henri Portier, professor

Correspondence to: Dr Chavanet.

BMF 1992;305:921-5 main limitation of amphotericin. Indeed, infusion related toxicity is very frequent (up to $80 \%$ of cases)

Amphotericin remains the standard treatment of the main systemic mycoses.' In patients infected with HIV and aspergillosis is inch candidiasis are very freq zole are widely used, incomplete response or failures of these treatments or decreased susceptibility of yeasts are increasing. ${ }^{-11}$ In these situations amphotericin and includes chills, fever, and nausea, nephrotoxicity being the most severe limiting factor. ${ }^{12-16}$ Other side effects, such as cardiac arrhythmia, are rare. ${ }^{\prime \prime \prime} 1^{-1}$

Amphotericin is a lipophilic drug that binds to sterols and intercalates among lipid bilayers. These $\overrightarrow{0}$ properties suggest that amphotericin should be suitable for use with a lipid based delivery system. Indeed, its incorporation with or use in association with liposomes or lipid complexes reduces toxicity such that the therapeutic index is increased..$^{14}$

Kirsh et al reported that mixing the parenteral lipid emulsion Intralipid with amphotericin greatly reduces amphotericin related toxicity both in vitro and in vivo." Since in routine practice these two compounds are widely given together (but through different catheters) we decided to prepare amphotericin directly in the lipid emulsion. We report a randomised clinical trial comparing the tolerance and efficacy of amphotericin deoxycholate (Fungizone) prepared either in Intralipid $20 \%$ or in glucose in HIV patients with candidiasis. The pharmacokinetics of these two formulations were also investigated.

\section{Patients and methods}

Patients were eligible for the study if they were aged 18 or over, infected with HIV, and had oral candidiasis. Patients were excluded if they had oesophagitis, oral Kaposi's sarcoma, known intolerance of amphotericin, pancreatitis, hyperlipidaemia, or a serum creatinine concentration above $115 \mu \mathrm{mol} / \mathrm{l}$. All eligible patients gave signed informed consent. The protocol was accepted by the local ethics committee. All patients included in the study were hospitalised in our medical unit.

Treatment-Amphotericin deoxycholate was dissolved either in 5\% glucose at a final concentration of $1.6 \mathrm{~g}$ amphotericin/l (amphotericin-glucose) or in parenteral fat emulsion (Intralipid 20\%) at a final concentration of $2 \mathrm{~g}$ amphotericin/l (amphotericin-fat emulsion). Whatever the preparation, amphotericin was given as a one hour infusion of $1 \mathrm{mg} / \mathrm{kg} /$ day on four consecutive days. ${ }^{1314212+}$ The rationale for using $1 \mathrm{mg} /$ $\mathrm{kg} / \mathrm{day}$ was the need to attain sufficiently bioactive concentrations. ${ }^{2 \xi}$ No premedication was given before the infusions. Amphotericin was infused into a peripheral $(n=9)$ or central $(n=13)$ vein. No other antifungal drug was given nor any intravenous lipid emulsion for parenteral nutrition. Hydration and electrolyte supplementation were given as needed. Magnesium supplementation was not given. After giving informed consent patients were assigned randomly to one of the two treatment groups. Group selection was determined by sequential assignment from a table of random numbers, by using the sealed envelope technique. Each envelope was opened immediately before the treatment was given. The treatments could not be given in blind fashion since the lipid emulsion has a distinctive milky appearance.

Assessment of tolerance-Clinical tolerance was monitored by using a standard data form. Sweating, chills, fever (defined as a temperature above $37 \cdot 5^{\circ} \mathrm{C}$ 
and rise of more than $1{ }^{\circ} \mathrm{C}$ during the infusion), nausea, pulse rate, and systolic and diastolic blood pressure were recorded at the beginning, middle, and end of the infusion and one hour afterwards. Mean blood pressure was calculated as follows: mean blood pressure $=$ (diastolic blood pressure + (systolic blood pressurediastolic blood pressure)/3). At these times the transcutaneous saturation of oxygen was measured (OSP200 apparatus, SATLITEtrans, Datex, Helsinky, Finland). Biological tolerance was monitored by daily electrolyte and creatinine measurements. In addition, full blood count; magnesium, triglyceride, and cholesterol concentrations; aspartate and alanine aminotransferase, $\gamma$-glutamyltransferase, lipase, and amylase activities; and electrocardiograms were obtained on davs 1 and 5. Amphotericin was stopped if severe clinical side effects occurred or if the creatinine concentration reached $159 \mu \mathrm{mol} / \mathrm{l}$. Paracetamol ( $1 \mathrm{~g}$ orally or intravenously) or dexamethasone $(4 \mathrm{mg})$ were given if severe chills or fever occurred during or after the infusion.

Assessment of efficacy-We devised a simple clinical score to monitor the state of the oral candidiasis. Each day the following nine sites were inspected for the presence or absence of candidiasis: upper, right, and left sides of the tongue; left and right sides of the jaw; both tonsil regions; and the smooth and hard portions of the palate. Each site was examined for confluent, patchy, or scattered lesions, which were scored 3, 2, and 1 respectively. Thus a clinical score could be calculated daily. A swab of one or two lesions was taken for mycological analysis before and at the end of treatment.

Pharmacokinetics-Serum samples were obtained daily before (trough) and five minutes (peak) and 12 hours after the one hour infusion of amphotericin and stored at $-20^{\circ} \mathrm{C}$ till assayed. Amphotericin was bioassayed with Paecilomyces varioti used as test organism. ${ }^{13}$ Sensitivity of the assay was $0.2 \mathrm{mg} / \mathrm{l}$; within day and between day variations were $8 \%$ at 0.5 $\mathrm{mg} / \mathrm{l}$ and $4 \%$ at $1.5 \mathrm{mg} / \mathrm{l}$. Area under the curve was calculated by the trapezoid method. The following formulas were used to calculate the pharmacokinetic parameters. Total body clearance $(1 / \mathrm{kg} / \mathrm{h})$ was calculated as dose divided by the area under the curve, volume of initial distribution $(1 / \mathrm{kg})$ was calculated as dose/concentration after the infusion; volume of distribution at steady state $(1 / \mathrm{kg})$ was calculated as clearance divided by $k$, where $k$ is the terminal rate constant; half life of elimination was calculated as $0 \cdot 693 / \mathrm{k}$.

Statistics - There is an $80-100 \%$ incidence of side effects with amphotericin-glucose $\mathrm{e}^{121 ; \leqslant 16}$ but only a $5 \%$ incidence of side effects with amphotericin-fat emulsion (personal data from pilot study). We decided that a $75 \%$ reduction in the incidence of side effects could be obtained with amphotericin-fat emulsion. For a type I error of less than $5 \%$ and statistical power of at least $95 \%$ we calculated that we should need to have 11 patients in each group. Discrete variables were compared by means of $\chi^{2}$ contingency analysis and Fisher's exact test. Continuous variables were compared by Student's $t$ test, one way analysis of variance on repeated measures as indicated, or the Mann-Whitney $\mathrm{U}$ test. A p value of $<0.05$ was taken as significant. Measurements are reported as means and SD.

\section{Results}

From June to December 1991, 22 patients (11 in each group) were enrolled in the study. The two groups were comparable for all the characteristics tested, including demographic variables, status of HIV infection and candidiasis, renal function and electrolyte equilibrium, and the concomitant use of other nephrotoxic drugs (table I)
TABLE I-Baseline characteristics of two groups of patients receiving amphotericin either in glucose or in parenteral fat emulsion

\begin{tabular}{|c|c|c|}
\hline & $\begin{array}{l}\text { Amphotericin- } \\
\text { glucose }\end{array}$ & $\begin{array}{l}\text { Amphotericin } \\
\text { fat emulsion }\end{array}$ \\
\hline No of patients & 11 & 11 \\
\hline Nomale & 11 & 9 \\
\hline Mean $(\mathrm{SD})$ age vears & 35,7 & $34(7)$ \\
\hline Mean (SD) weight $(\mathrm{kg}$ ) & 618 & $53 \div$ \\
\hline \multicolumn{3}{|c|}{ Centres for Disease Control classification of HIV No of patients): } \\
\hline IV C2 & 3 & 3 \\
\hline IV D & 0 & 1 \\
\hline IV Cl & 8 & 7 \\
\hline \multicolumn{3}{|l|}{ Concurrent treatment (No of patients): } \\
\hline Zidovudine & 8 & 6 \\
\hline Foscarnet & 1 & 1 \\
\hline Co-trimoxazole & 2 & 2 \\
\hline Pyrimethamine & 3 & 5 \\
\hline Sulphadiazine & 2 & 3 \\
\hline Mean $(\mathrm{SD})$ white cell count $\left(\times 10^{6} / 1\right)$ & $3445(1747)$ & $2809(1+44)$ \\
\hline Mean $(\mathrm{SD}) \mathrm{CD} 4 \mathrm{count}\left(\times 10^{6} / 1\right)$ & $121(161)$ & $48(88)$ \\
\hline Mean SD creatinine $u \mathrm{~mol} / 1$ & $79 \cdot 6(13 \cdot 1)$ & $77 \cdot 8(19 \cdot 4)$ \\
\hline Mean (SD) potassium $(\mathrm{mmol} / \mathrm{l}$ & $3 \cdot 8 \cdot 0 \cdot 3$ & $3 \cdot 9: 0 \cdot 3$ \\
\hline \multicolumn{3}{|l|}{ Mean $(\mathrm{SD})$ magnesium $(\mathrm{mmol} / \mathrm{l})$ : } \\
\hline Serum & $10 \cdot 7: 1 \cdot 4$ & $10 \cdot 8(1 \cdot 5)$ \\
\hline Erythrocytes & $24 \cdot 513 \cdot 0$ & $29 \cdot 5,10 \cdot 5$ \\
\hline \multicolumn{3}{|l|}{ Oral candidiasis: } \\
\hline Prior treatment Fluconazole & 7 & 6 \\
\hline Candida albicans & $\begin{array}{l}1 \\
9\end{array}$ & $\begin{array}{r}2 \\
10\end{array}$ \\
\hline Fungal strain $f_{\text {Other }}$ & 2 & 1 \\
\hline Mean SD) clinical score* & $6 \cdot 0+7)$ & $6 \cdot 3(4)$ \\
\hline
\end{tabular}

* See methods.

All the amphotericin-fat emulsion infusions were given without serious problem whereas four amphotericin-glucose treatments were stopped. Two patients had shaking chills during the first two amphotericinglucose infusions and three patients had a striking increase in creatinine concentration $(>159 \mathrm{umol} / \mathrm{l})$ on dav 3 (one of whom also had chills). All these renal insufficiencies reversed within a few days.

Clinical side effects were much more frequent with amphotericin-glucose than with amphotericin-fat emulsion (36 per 38 infusions $(94 \cdot 7 \%$ ) $v 10$ per 44 $(22 \cdot 7 \%) ; p=0.0001$ ( $\gamma^{\prime}$ test $\left.)\right)$. Only two patients receiving amphotericin-glucose $(18 \% \quad(95 \%$ confidence interval $2 \cdot 2 \%$ to $37 \%)$ ) were free of clinical reaction compared with eight in the amphotericin-fat emulsion group $(72 \%(50 \%$ to $94 \%) ; p=0.03$ (Fisher's exact test)). Moreover, the reactions were severe enough to warrant treatment (paracetamol, dexamethasone) in five patients given amphotericin-glucose $(45.5 \%) \mathrm{com}$ pared with none given amphotericin-fat emulsion $(p=0.04$ (Fisher's exact test)). Chills and fever were the most frequent side effects $-66 \%$ (25) in the amphotericin-glucose group versus $4 \%$ (2) in the amphotericin-fat emulsion group $(\mathrm{p}=0.001$ (Fisher's exact test)). Seven patients given amphotericin-glucose complained of chills compared with one given amphotericin-fat emulsion ( $p=0.001$ (Fisher's exac test)). The same picture was observed with fever (seven patients given amphotericin-glucose compared with one given amphotericin-fat emulsion $(p=0.001$ Fisher's exact test)). Five of the seven patients given amphotericin-glucose had both chills and fever whereas these side effects occurred in different patients in the amphotericin-fat emulsion group. Sweating and nausea were slightly less frequent in the amphotericinfat emulsion group (table II).

There were no significant variations in pulse rate, blood pressure, or transcutaneous oxvgen saturation either during the infusions or during the whole treatment course (table III). No electrocardiographic abnormalities were seen before or after amphotericin.

With respect to patients who completed the four days of treatment the mean increase in creatinine concentration from baseline (table II) was higher in the amphotericin-glucose group (42 (SD 31) $\mu \mathrm{mol} / \mathrm{l} v$ $14(19) \mu \mathrm{mol} / \mathrm{l})$. The daily increase in creatinine concentration was also higher in this group $(p=0.01$ (one way analvsis of variance on repeated measures, 
not shown)). The numbers of patients with at least one creatinine value $\geqslant 133 \mu \mathrm{mol} / 1$ during the five days of observation were four among seven compared with one among 11 for patients given amphotericin-fat emulsion $(\mathrm{p}=0.04$ (Fisher's exact test)). No significant variation in potassium or sodium value was observed in either group. Magnesium concentration was not decreased with amphotericin-fat emulsion whereas a significant decrease in serum and erythrocyte magnesium concentrations was observed with amphotericin-glucose (table II). No correlation was found between the variations in magnesium concentration and renal function in patients who completed treatment with amphotericin-glucose (not shown).

Triglyceride concentrations at day 0 and day 5 were not appreciably different in the two groups $(1.4$ (SD $0.6)$ and $1.9(0.6) \mathrm{mmol} / \mathrm{l}$ in the amphotericin-glucose group; $1.6(0.8)$ and $1.5(0.7) \mathrm{mmol} / 1$ in the amphotericin-fat emulsion group). Serum cholesterol concentrations also were very similar in the two groups at entry and day $5(3.6(1.6)$ and $3.3(0.8) \mathrm{mmol} / \mathrm{l}$ in the amphotericin-glucose group; $3.7(1.5)$ and 3.7 $(0.7) \mathrm{mmol} / \mathrm{l}$ in the amphotericin-fat emulsion group). Platelet and white cell counts, haemoglobin concentration, and serum aminotransferase, $\gamma$-glutamyltransferase, lipase, and amylase activities were not appreciably different in the two groups at entry and did not change after completion of either amphotericin treatment (not shown).

Applying our clinical score of oral candidiasis showed the two groups to be comparable (table I). All the patients improved with either treatment. The reduction in clinical score of oral candidiasis was similar in the two groups (3.5 (SD 5) in the amphotericin-fat emulsion group; $4 \cdot 6(6)$ in the amphotericin-

TABLE II-Side effects of amphotericin $1 \mathrm{mg} / \mathrm{kg} /$ day in one hour infusion for four days prepared either in glucose or in Intralipid $20 \%$

\begin{tabular}{|c|c|c|}
\hline & $\begin{array}{l}\text { Amphotericin- } \\
\text { glucose }\end{array}$ & $\begin{array}{l}\text { Amphotericin- } \\
\text { fat emulsion }\end{array}$ \\
\hline No of patients & 11 & 11 \\
\hline No having interruption of treatment & 4 & $0^{\star}$ \\
\hline Day of interruption (No of patients) & Day 2(1), day 3(3) & \\
\hline \multicolumn{3}{|l|}{ Causes of interruption (No of patients): } \\
\hline Chills & 2 & \\
\hline Creatinine $>159 \mu \mathrm{mol} / \mathrm{l}$ & 3 & \\
\hline No of infusions & 38 & 44 \\
\hline \multicolumn{3}{|l|}{ No of patients without any clinical } \\
\hline Total No of clinical side effects & 36 & $10^{\star}$ \\
\hline Chills & 15 & 1 \\
\hline Sweats & 5 & 4 \\
\hline Fever & 10 & 1 \\
\hline Nausea & 6 & 4 \\
\hline \multicolumn{3}{|l|}{ Mean (SD) creatinine $(\mu \mathrm{mol} / \mathrm{l}) \dagger:$} \\
\hline Day 0 & $79 \cdot 6(13 \cdot 3)$ & $77 \cdot 8(19 \cdot 4)$ \\
\hline Day 5 & $121 \cdot 1(31 \cdot 8)$ & $91.9(23.9) \ddagger$ \\
\hline \multicolumn{3}{|l|}{ No of patients with at least one } \\
\hline during treatment $\dagger$ & 4 & $1^{\star}$ \\
\hline \multicolumn{3}{|c|}{ Mean (SD) change of magnesium $(\mathrm{mmol} / \mathrm{l})$ : } \\
\hline Serum & $-1 \cdot 22(1 \cdot 7)$ & $0.22(1 \cdot 2) \Omega$ \\
\hline Erythrocytes & $-6 \cdot 7(9 \cdot 5)$ & $0.6(4 \cdot 3)$ \\
\hline
\end{tabular}

${ }^{\star} p \leqslant 0.05$ With Fisher's exact test.

tThe four patients whose treatments were stopped were not included.

$\neq$ Comparison between treatments significant at $p=0.04$ (analysis of variance) from days 3 to 5

$p=0.05$ With Student's $t$ test.

$\| \mathrm{p}=0.03$ With Mann-Whitney U test.
TABLE IV-Comparative pharmacokinetic parameters of amphotericin $1 \mathrm{mg} / \mathrm{kg} /$ day in one hour infusion on four days prepared either in glucose or in parenteral fat emulsion

\begin{tabular}{|c|c|c|}
\hline & $\begin{array}{l}\text { Amphotericin- } \\
\text { glucose }\end{array}$ & $\begin{array}{l}\text { Amphotericin- } \\
\text { fat emulsion }\end{array}$ \\
\hline Mean $(\mathrm{SD})$ area under curve $(\mathrm{mg} / \mathrm{h})$ & $21 \cdot 9(8)$ & $12 \cdot 6(4 \cdot 4)^{\star}$ \\
\hline $\begin{array}{l}\text { Mean (SD) total body clearance at day } 4 \\
(\mathrm{~V} / \mathrm{kg} / \mathrm{h})\end{array}$ & $0.509(0.0176)$ & $0 \cdot 879(0 \cdot 030$ \\
\hline $\begin{array}{l}\text { Mean (SD) half life of elimination at } \\
\text { day } 4(\mathrm{~h})\end{array}$ & $12 \cdot 7(3 \cdot 2)$ & $11 \cdot 6(4 \cdot 3)$ \\
\hline \multicolumn{3}{|l|}{ Mean (SD) volume of distribution $(1 / \mathrm{kg})$ : } \\
\hline Day 1 & 0.795 & $1.544(0.56$ \\
\hline Day 4 & $0.916(0.381)$ & $1.6(1.06)$ \\
\hline
\end{tabular}

${ }^{\star} \mathrm{p}=0.01$ With Mann-Whitney U test.

$t \mathrm{p}=0.0046$ With Mann-Whitney U test.

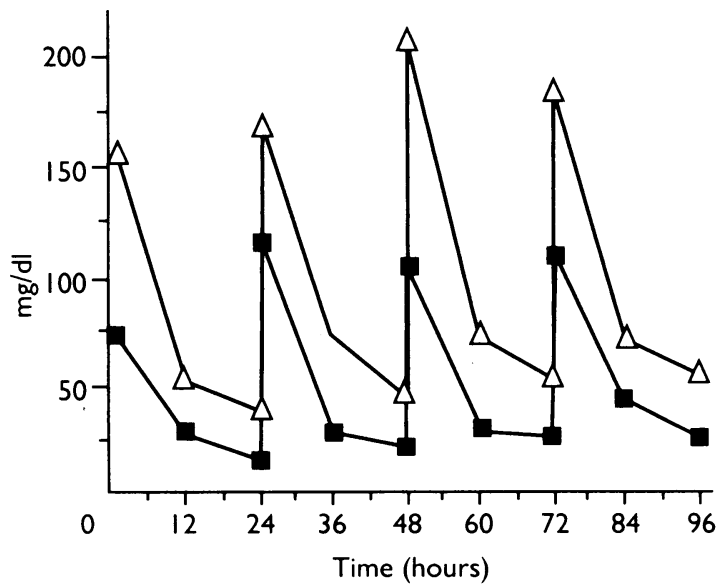

Pharmacokinetics of amphotericin $1 \mathrm{mg} / \mathrm{kg}$ daily given as one hou infusion on four days prepared either in glucose $(\Delta)$ or in parenteral fai emulsion (-). (Blood was sampled for bioassay before, at end, and 12 hours after each infusion of amphotericin. Results are means of data from nine patients in each group)

glucose group $(\mathrm{p}=\mathbf{0} \cdot 38 ;$ Mann-Whitney $\mathrm{U}$ test $))$. Only two patients in each group had a sterile swab at the completion of treatment, including a patient in the amphotericin-fat emulsion group whose swab at day 1 had grown Candida tropicalis. Only one patient given amphotericin-fat emulsion had Torulopsis glabrata isolated at day 5 ; in all the other patients $C$ albicans was isolated at both day 1 and day 5 .

Amphotericin concentrations at trough, peak, and 12 hours after the daily infusion and at day 5 (last trough) were available for nine patients in each group (figure). There were significant differences in each of these three concentrations between treatments $(p=$ 0.01 for peak and 12 hour concentrations; $p=0.0024$ for trough concentrations (analysis of variance on repeated measures)). The area under the curve was greater for amphotericin-glucose than for amphotericin-fat emulsion (table IV). Total body clearance on the fourth day of treatment and the volume of initia distribution were significantly higher with amphotericin-fat emulsion than with amphotericin-glucose whereas the volume of distribution at steady state (day 4) was slightly higher with amphotericin-fat emulsion (NS; table IV). The half life at day 4 was similar with the two preparations.

TABLE III - Haemodynamic tolerance of amphotericin $1 \mathrm{mg} / \mathrm{kg} /$ day in one hour infusion for four days prepared either in glucose or in parenteral fa emulsion

\begin{tabular}{|c|c|c|c|c|c|c|}
\hline & & \multirow[b]{2}{*}{$\begin{array}{c}\text { Baseline } \\
\text { value }\end{array}$} & \multicolumn{4}{|c|}{ Changes at: } \\
\hline & & & Day 1 & Day 2 & Day 3 & Day 4 \\
\hline \multirow[b]{2}{*}{ Mean (SD) pulse (beats/min) } & Amphotericin-glucose & $\{90(15)$ & $-6 \cdot 3(24)$ & $-7 \cdot 1(22)$ & $-11.9(33)$ & $-13(34)$ \\
\hline & Amphotericin-fat emulsion & $\{78(15)$ & $0.4(8.5)$ & $-2 \cdot 8(9 \cdot 7)$ & $-1 \cdot 3(8 \cdot 8)$ & $3 \cdot 3(11)$ \\
\hline \multirow{2}{*}{ Mean $(\mathrm{SD})$ blood pressure $(\mathrm{mm} \mathrm{Hg})$} & Amphotericin-glucose & $\{90(15)$ & $-0 \cdot 7(1)$ & $-0 \cdot 3(1 \cdot 1)$ & $1 \cdot 2(1 \cdot 8)$ & $0(1 \cdot 3)$ \\
\hline & Amphotericin-fat emulsion & $192(18)$ & $0.3(1.6)$ & $0.8(1 \cdot 3)$ & $0 \cdot 2(1 \cdot 3)$ & $0.5(1.4)$ \\
\hline \multirow{2}{*}{$\begin{array}{l}\text { Mean (SD) transcutaneous saturation } \\
\text { of oxygen }(\%)\end{array}$} & Amphotericin-glucose & $\{97(4)$ & $0.3(1.5)$ & $0(2 \cdot 9)$ & $0 \cdot 8(3 \cdot 4)$ & $-1 \cdot 2(5 \cdot 1)$ \\
\hline & Amphotericin-fat emulsion & $198(1)$ & $-0 \cdot 8(2)$ & $0.4(1.5)$ & $-2(9)$ & $0 \cdot 9(2)$ \\
\hline
\end{tabular}

The three haemodynamic measurements were done at end of each infusion. 


\section{Discussion}

The main finding of our study was that the combination of amphotericin deoxycholate with a parenteral lipid emulsion is much better tolerated than amphotericin prepared in glucose. Indeed, in this study clinical side effects were fourfold to 16 -fold less frequent with amphotericin-fat emulsion than with amphotericin-glucose. There were no differences in blood pressure or pulse rate between the two treatmen groups. ${ }^{2+}$ Moreover, renal impairment occurred in seven of the 11 patients who received amphotericinglucose compared with only one of the 11 who received amphotericin-fat emulsion. There was a fall in magnesium values in serum and erythrocytes in patients given amphotericin-glucose but not in patients given amphotericin-fat emulsion.

Experience suggests that a prolonged duration of infusion should result in fewer side effects associated with infusion. Several case reports and one randomised study, however, did not confirm this with respect to amphotericin. ${ }^{13} 1521-242628$ Furthermore, the toxicity of amphotericin-glucose observed in this study was similar to that usually recorded. ${ }^{1}{ }^{121315162129}$ On the other hand, both the efficacy and toxicity of amphotericin in vitro are considered to be concentration dependent. ${ }^{13}$ Hence rapid intravenous injections, which give higher serum concentrations, ${ }^{26}$ could be more toxic. We failed to find any correlation between serum amphotericin concentrations and either clinical effects and serum creatinine values or magnesium concentrations in patients receiving amphotericin glucose (not shown). Thus we cannot incriminate the brief duration (one hour) of the infusion to explain the observed toxicity of amphotericin-glucose. Therefore, the comparison between the two formulations of amphotericin is valid and clinically useful.

Some of the reported reactions with amphotericin are probably mediated by tumour necrosis factor or prostaglandin release. ${ }^{30}{ }^{31}$ Probably they are also related to the direct effects of free amphotericin on mammalian cells. ${ }^{32-35}$ We speculated that parenteral fat emulsion might act as other lipid structures in reducing the toxicity of amphotericin, ${ }^{19} 2034$ and in this respect our clinical findings confirm experimental data obtained in vitro and in vivo. Indeed, parenteral fat emulsion reduced amphotericin related toxicity in erythrocytes ${ }^{20}$ and human renal tubular cells ${ }^{35}$ and renal toxicity in rats..$^{20}$ Furthermore, the maximal tolerated dose in mice was ninefold higher with amphotericin-fat emulsion than with amphotericin alone. ${ }^{20}$

We expected a very low incidence of toxicity related to the parenteral fat emulsion itself, given the small volume infused. Indeed, although nausea could be related to the fat emulsion, no increase in hepatic or pancreatic enzyme activities was observed. ${ }^{36} 37$

Amphotericin is easy to prepare in parenteral fat emulsion and is chemically stable, ${ }^{20}$ cost effective, and well tolerated at a dose of $1 \mathrm{mg} / \mathrm{kg} /$ day for four consecutive days. However, further studies are warranted to investigate the tolerance of this mixture over a longer period of treatment.

The pharmacokinetic analysis of amphotericin was based on only three samples per day, and plainly our results with respect to amphotericin-glucose were very similar to those previously reported. ${ }^{13233839}$ Conversely, the pharmacokinetics of amphotericin were modified when the drug was prepared and infused with parenteral fat emulsion. Indeed, all calculated parameters indicated that the diffusion of amphotericin-fat emulsion was greater than the diffusion of amphotericin-glucose. It is of particular interest that the volume of initial distribution of amphotericin-fat emulsion was twice that of amphotericin-glucose whereas the difference was not so great for the volume of distribution at steady state. This could indicate that the diffusion of amphotericin-fat emulsion is much more rapid than the diffusion of amphotericin-glucose. This could have clinical implications for the treatment of tissue infections.

We did not set out to compare the relative efficacy of amphotericin-glucose and amphotericin-fat emulsion on mucosal candidiasis in patients infected with HIV. Nevertheless, we note that the reduction in the clinical score of candidiasis was similar with both treatments. This supports the argument that egg lecithins (a major component of parenteral fat emulsion) do not alter the bioactivity of amphotericin ${ }^{40}$ and confirms in vitro ${ }^{41}$ and in vivo experimental data on both candidal and cryptococcal infections $^{20+1}$ (V Joly, L Saint-Julien, C Carbon, P Yeni, paper presented to 31st interscience conference on antimicrobial agents and chemotherapy, Chicago, 29 September to 2 October, 1991 (abstract 578)). More importantly, a pilot study of amphotericin-fat emulsion in our institution in patients with neutropenia showed that this formulation is effective against candidaemias. Similarly, we have recorded cure of candidal oesophagitis in patients with HIV

\section{Conclusion}

We conclude that the clinical and renal tolerance of amphotericin is dramatically improved when the drug is prepared and infused in parenteral fat emulsion. This simple and cost effective preparation of amphotericin avoids the usual need for escalating doses. In addition, its efficacy in candidal infection is similar to that of conventional amphotericin at the same dosage.

These results prepare the way for further controlled and comparative studies of amphotericin-fat emulsion in different clinical settings. For example, investigations could be done to shorten antifungal treatment by giving the full dose at once, to increase the daily dose of amphotericin, or to lengthen the duration of amphotericin treatment.

Finally, the respective benefits, limits, and indications for amphotericin-glucose, amphotericin-fat emulsion, and the new liposomal formulations of amphotericin remain to be investigated.

1 Gallis H, Drew R, Pickard W. Amphotericin B: 30 vears of clinical experience. Rev Infect Dis 1990;12:308-28

2 Feigal F, Katz M Greenspan D, Wetenhouse J, Winkelstein W, Lang W, et al. The prevalence of oral lesions in HIV-infected homosexual and bisexual men: three San Francisco epidemiological cohorts. AIDS 1991;5: $519-25$

3 Diamond $\mathrm{R}$. The growing problem of mycoses in patients infected with the human immunodeficiency virus. Rev Infect Dis 1991;13:480-6.

4 Barone R, Ficarra G, Gaglioti D, Orsi A, Mazzotta F. Prevalence of oral lesion among HIV-infected intravenous drug abusers and other risk groups. Oral Surg Oral Med Oral Pathol 1990;69:169-73.

5 Leibovitz E, Rigaud M, Chandwani S, Kaul A, Greco A, Pollack H, et al. Disseminated fungal infections in children infected with human immunodeficiency virus. Pediatr Infect Dis 7 1991; 10:888-94.

6 Denning D, Follanbee S, Scolaro M, Norris S, Edelstein H, Stevens D. Pulmonary aspergillosis in the acquired immunodeficiency syndrome. NEnglf Med 1991;324:654-62.

7 Evans T, Mayer J, Cohen S, Classen D, Carroll K. Fluconazole failure in the treatment of invasive mycoses. I Infect Dis 1991;164:1232-5.

8 Smith D, Midgley J, Allan M, Connolly G, Gazzard B. Itraconazole versus ketoconazole in the treatment of oral and oesophageal candidosis in patients infected with HIV AIDS 1991:5:1367-71.

9 Tavitian A, Raufman J, Rosenthal L, Weber J, Webber C, Dinscoy H. Ketoconazole-resistant candida esophagitis in patients with acquired immunodeficiency syndrome. Gastroenterology 1986;90:443-5.

10 Dupouy-Camet J, Paugam A, Tourte-Scheaffer C. Yeast susceptibility testing. Lancet 1991;338:383.

11 Kadende P, Laroche R, Ndabaneze E, Marerwa G, Habonimana D, Floch JJ, et al. AIDS-related esophagal candidosis in Africa. Pilot study in Burund with fluconazole. Journal de Mycologie Médicale 1991;1:189-92.

12 Butler W, Bennett J, Alling D, Wertlake P, Utz J, Hill G. Nephrotoxicity of amphotericin B. Early and late effects in 81 patients. Ann Intern Med 1964;61:175-87.

13 Bindschadler D, Bennett J. A pharmacologic guide to the clinical use of amphotericin B. F Infect Dis 1969;120:427-36.

14 Perfect J, Pickard W, Hunt D, Palmer B, Schell W. The use of amphotericin $\mathrm{B}$ in nosocomial fungal infection. Rev Infect Dis 1991;13:474-9.

15 Utz J, Bennett J, Brandiss M, Butler W, Hill G. Amphotericin B toxicity. Ann Intern Med 1964;61:334-54.

16 Warnock D. Amphotericin B: an introduction. 7 Antimicrob Chemother 1991;28(suppl B):27-38. 
17 DeMonaco J, McGovern B. Transient asystole associated with amphotericin B infusion. Drug Intell Clin Pharm 1983;17:547-9.

18 Craven P, Gremillion D. Risk factors of ventricular fibrillation during rapid amphotericin B infusion. Antimicrob Agents Chemother 1985;27:868-71.

19 Braitburg J, Powderly W, Kobayashi G, Medoff G. Amphotericin B: delivery systems. Antmicrob Agents Chemother 1990;34:381-4

20) Kirsh R, Goldstein R, Tarloff J, Parris D, Hook J, Hanna N, et al. An emulsion formulation of amphotericin $\mathrm{B}$ improves therapeutic index when treating systemic murine candidiasis. F Infect Dis 1988;158:1065-70

21 Barreuther A, Dodge R, Blondeaux A. Administration of amphotericin B Drug Intell Clin Pharm 1977;11:368-9.

22 Cleary J, Weisdorf D, Fletcher C. Effect of infusion rate on amphotericin B-associated febrile reactions. Drug Intell Clin Pharm 1988;22:769-72.

23 Emminger E, Lang $\mathrm{H}$, Emminger-Schmidmeier W, Peters C, Gadner $\mathrm{H}$ Amphotericin B serum levels in pediatric bone marrow transplant recipients. Bone Marrow Transplant 1991:7.95-9.

24 Olfield E, Garst P, Hostetter C, White M, Samuelsson D. Randomised, double-blind trial of 1 - versus 4-hour amphotericin B infusion durations. double-blind trial of 1 - versus 4-hour amphor

25 Colletre N, Van Der Auwera P, Pascual Lopez A, Heymans C, Meunier F. Tissue concentrations and bioactivity of amphotericin $\mathrm{B}$ in cancer patients Tissue concentrations and bioactivity of amphotericin B in cancer patients
treated with amphotericin B-deoxycholate. Antimicrob Agents Chemother 1989;33:362-8.

26 Fields B, Bates J, Abernathy R. Effect of rapid intravenous infusion on serum concentrations of amphotericin B. Applied Microbiology 1971;22:615-7.

27 Casagrande J, Pike M, Smith P. An improved approximate formula for calculating sample sizes for comparing two binomial distributions. Biometrics 1978;34:483-6.

28 Tarala R, Smith J. Cryptococcosis treated by rapid infusion of amphotericin B. BMF 1980;281:28.

29 Kan V, Bennett J, Amantea M, Smolskis MC, McMlanus E, Grasela DM, et al. Comparative safety, tolerance, and pharmacokinetics of amphotericin $B$ lipid complex and amphotericin B deoxycholate in healthy male volunteers. I Infect Dis 1991; 164:418-21.

30 hia J, McManus E. In vitro tumor necrosis factor induction assay for analysis this 7 of febrile toxicity associated with amphotericin B preparations. Antimicrob Agents Chemother 1990:34:906-8.

31 Gigliotti $F$, Shenep J, Lott L, Thornton D. Induction of prostaglandin synthesis as the mechanism responsible for chills and fever produced by infusion of amphotericin B. I Infect Dis 1987;156:784-9.

32 Bolard $\mathrm{J}$. How do the polyene macrolide antibiotics affect the cellular membrane properties? Biochem Biophys Acta 1986;864:257-304

33 Brajtburg J, Powderly W, Kobayashi G, Medoff G. Amphotericin B: current understanding of mechanisms of action. Antimicrob Agents Chemother 1990;34:183-8

34 Janoff A, Boni L, Popescu M, Minche SR, Cullis PR, Madden TD, et al. Unusual lipid structures selectively reduce the toxicity of amphotericin B. Proc Natl Acad Sci USA 1988;85:6122-6.

35 Joly V, Bolard J, Saint-Julien L, Carbon C, Yeni P. Influence of phospholipid/ amphotericin $B$ ratio and phospholipid type on in vitro renal cell toxicities and fungicidal activities of lipid-associated amphotericin B formulations. Antimicrob Agents Chemother 1992;36:262-6.

36 Jarnum S, Ladefoged $\mathrm{K}$. Long term parenteral nutrition I: clinical experience in 70 patients from 1967 to 1980 . Scand f Gastroenterol 1981;16:903-11.

37 Messing B, Latrive J, Bitoun A, Gallian A, Bernier J. La steatose hepatique au cours de la nutrition parenterale totale depend-elle de l'apport calorique lipidique? Gastroenterol Clin Biol 1979;3:719-24.

38 Atkinson A Bennett J. Amphotericin B pharmacokinetics in humans. Antimicrob Agents Chemother 1978;13:271-6.
Atinson A, Bennett J. Amphotericin B

39 Christiansen K, Bernard E, Gold J, Armstrong D. Distribution and activity of amphotericin B in humans. F Infect Dis 1985;152:1037-43.

40 Brajtburg J, Elberg S, Kobayashi G, Medoff G. Inhibition of amphotericin B (Fungizone) toxicity to cells by egg lecithin-glycocholic acid micelles. Antimicrob Agents Chemother 1990;34:2415-6.

41 Chavanet P, Charlier N, Brenet A, Goux A, Muggeo E, Caillot D, et al. Emulsion of amphotericin B in Intralipid 20\%: in vitro and in vivo efficacy. Path Biol 1992;40:507-12.

(Accepted 20 August 1992)

\title{
Vitamin $\mathbf{C}$ depletion and pressure sores in elderly patients with femoral neck fracture/
}

\author{
Helen FGoode, Eileen Burns, Barry E Walker
}

\section{Abstract}

Objective-To evaluate the contribution of specific nutritional deficiencies (as indicated by zinc; vitamin $A, C$, and $E$; albumin; and haemoglobin concentrations) to the risk of pressure sores.

Design-Observational cohort study.

Setting-St James's University Hospital, Leeds.

Subjects -21 elderly patients presenting consecutively to the orthopaedic unit with femoral neck fracture.

Main outcome measure-Full thickness epidermal break over a pressure bearing surface.

Results -10 patients $(48 \%)$ developed a pressure sore during their hospital stay. Indices of zinc status and concentrations of albumin, haemoglobin, and vitamins $A$ and $\mathbf{E}$ were similar in patients who developed a pressure sore and those who did not. Mean leucocyte vitamin $\mathbf{C}$ concentration, however, was $6.3(S D 2.2) \mu \mathrm{g} / 10^{8}$ cells in patients who developed a pressure sore as compared with 12.8 (4.6) $\mu \mathrm{g} / 10^{8}$ cells in patients who did not.

Conclusions-Low concentrations of leucocyte vitamin $C$ appear to be associated with subsequent development of pressure sores in elderly patients with femoral neck fractures.

James's University Hospital, Leeds)LS9 7TF Helen F Goode, senior clinical (research) scientist Barry E Walker, consultan physician

Department of Medicine for the Elderly, Leeds General Infirmary, Leeds LS1 3EX

Eileen Burns, consultant physician

Correspondence to: Dr Goode. blood pressure, and nutritional deficiency. Other factors, such as confusion and incontinence, may also be important. ${ }^{45}$

The benefits of supplementary nutritional support in patients with femoral neck fracture have been reported ${ }^{67}$ and there is evidence that undernutrition may be a predisposing factor in pressure sore development. ${ }^{8}$ However, the contribution of pre-existing specific nutritional deficiencies to the risk of pressure sore development has not been studied.

Zinc is an essential element which has a crucial role in immunity and healing and for which interactions with other vitamins have been described. ${ }^{9}$ Both topical and oral zinc supplementation have a beneficial effect on wound healing in zinc depleted subjects. ${ }^{10}$ Vitamin $\mathrm{C}$ has also been shown to promote wound healing and may have a role in immunological regulation. ${ }^{9}$ Elderly people are particularly at risk from both nutritional deficiencies and depressed immunity, and studies in this hospital have shown a high prevalence of zinc ${ }^{11}$ and vitamin ${ }^{12}$ depletion in elderly inpatients.

This study was undertaken to assess the contribution of nutritional status to the development of pressure sores in elderly patients with femoral neck fractures.

\section{Subjects and methods}

Twenty one unselected patients aged 75 or more admitted to the orthopaedic unit with a diagnosis of femoral neck fracture were invited to participate in the study, which was approved by the local clinical research (ethics) committee. Written informed consent was obtained from all patients or their next of kin. Pressure sores were defined as a full thickness epidermal break over a pressure bearing surface.

A preoperative fasting blood sample was obtained at 8-9 am on the day after admission for assay of various biochemical nutritional indices, including plasma and polymorphonuclear leucocyte zinc; plasma albumin 